\title{
Research of the manipulator dynamics installed on an elastic basis
}

\author{
Dmitriy Mishchuk \\ Kyiv National University of Construction and Architecture \\ Povitroflotsky avenue 31, Kyiv, Ukraine, 03037 \\ mischuk84@gmail.com, orcid.org/0000-0002-8263-9400 \\ Received 27.09.2018, accepted for publication 18.10.2018 \\ DOI: 10.26884/uwt1808.1301
}

\section{INTRODUCTION}

In many scientific articles on construction topics, the problem of building density has recently been considered $[1,2]$. When working construction equipment in the construction of such objects there is a problem of safety of work. For example, in work [3, 4] the possibility of an excavator with an offset digging axis is presented. But, such research for construction cranes and construction robots is not enough.

The elasticity of metal structures of real mechanical systems manipulators greatly affects their work [5]. When lifting cargo manipulator in its metal construction generated vibrations due to the complex dynamics of the machine. Fluctuations cargo the cause errors in its position and reduce life of the machine. For eliminate fluctuation make use of the dampers and devices regulate speed of the working body of the manipulator $[5,6]$.

\section{MATERIALS AND METHODS}

It is necessary to develop the dynamic and mathematical models of the boom of the manipulator, which is mounted on an elastic base.

The mathematical model must take into account the parameters of the rigidity of the support arm of the manipulator, the mass of the jet and the load, as well as its geometrical parameters.

The basic method of compiling the dynamic equations of motion, the Lagrange equations are used. The boundary conditions for the solution of the obtained differential equations for the angle of rotation the deformed prop were the boundary values of the displacements and the angle of rotation of the cantilever beam within the boundary of the strength of its cross-section.

\section{PRESENTATION OF RESEARCH MATERIAL}

Consider the dynamic system (Fig.1) of a manipulator with a hydraulic drive, in which the mass of $m$ arrows and load are concentrated on the end of a rigid arrow in length $l_{1}$.

The bottom of the arrow is fixed on one fixed hinge and through the support link of length $l_{2}$ on an elastic basis. On the model, the elastic base is depicted as a spring with stiffness $c$. The mass of the link $l_{2}$ is neglected. The model also does not take into account the damping of possible spring oscillations.

Changing the departure of the arrow of the manipulator occurs by rotating it around the fixed hinge by the introduction of the rod of the drive hydraulic cylinder, which is one end connected to the lifting arm, and the other is 
mounted on the support link. This leads to a change in its length $q$.

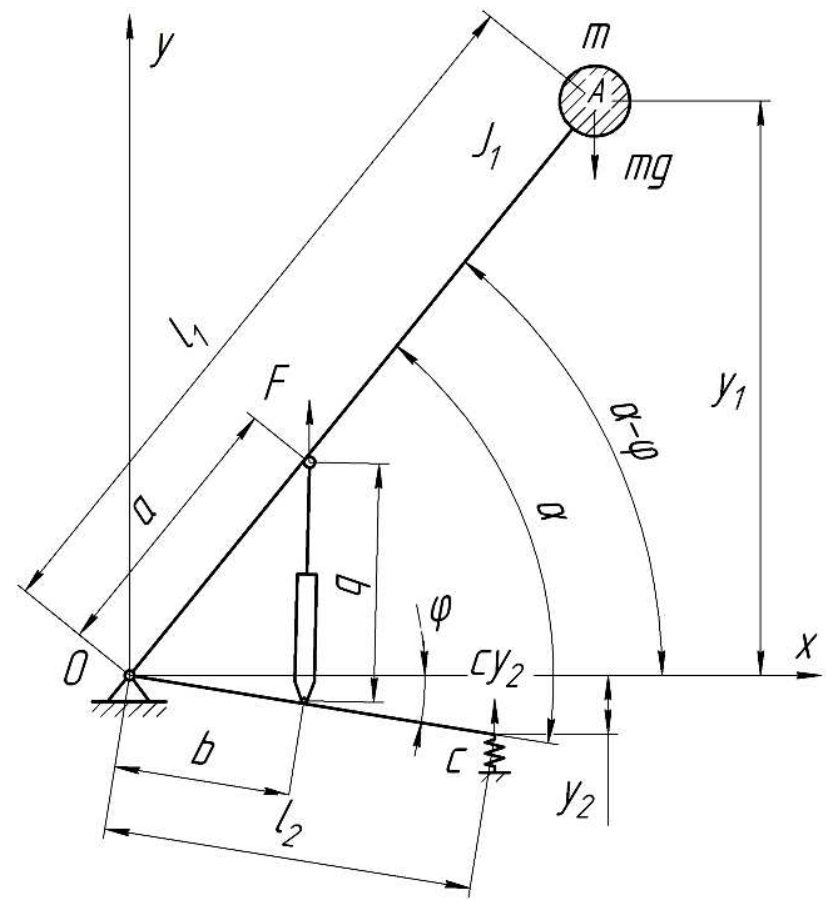

Fig.1. Simplified dynamic model of the manipulator

For the generalized coordinates of motion, the angle $\alpha$ of the rotation of the arrow and the angle $\varphi$ of the rotation of the reference link $l_{2}$ due to the deformation of the elastic support is assumed.

This approach to drawing of the dynamic model of the manipulator shown in scientific papers $[7,8]$ and is beyond doubt. However, in the examined robots, the oscillations of the boom of the manipulator without considering the elasticity of the base are studied.

The kinetic energy of the considered system is equal:

$$
T=\frac{1}{2} J_{1}(\dot{\alpha}-\dot{\varphi})^{2},
$$

where $\alpha$ and $\varphi$ are respectively the angles of rotation of the arrow from the injection of the hydraulic cylinder and from the deformation of the support; $J_{1}$ is an aggregate moment of inertia of the mass of the arrow and load.

Masa elastic strut is not considered. A dot above angular coordinates means time differentiation. Thus $\dot{\alpha}$ and $\dot{\phi}$ are angular velocities.
In simplified form, the moment of inertia $J_{1}$ will take into account as:

$$
J_{1}=\left(\frac{m_{1}}{3}+m\right) l_{1}^{2},
$$

where $m_{1}$ and $m$ are respectively the weight of the boom and load.

The potential energy of the system:

$$
\Pi=-m_{\Sigma} g y_{1}+\frac{c y_{2}^{2}}{2},
$$

where $m_{\Sigma}=\frac{m_{1}}{2}+m-$ consolidated mass of the system; $y_{1}$ is the vertical coordinate of the concentrated mass; $y_{2}$ is the coordinate of the deformation of the spring.

The vertical coordinate of the concentrated mass is equal:

$$
y_{1}=l_{1} \sin (\alpha+\varphi) \text {. }
$$

The spring coordinate of deformation is equal:

$$
y_{2}=l_{2} \sin \left(\varphi_{0}-\varphi\right) \approx l_{2}\left(\varphi_{0}-\varphi\right) \text {. }
$$

In the assumption of the holonomic pull according to the method of the Lagrange equation of the 2-nd kind, the differentiation of expressions (1) and (3) is made and the following system of equations is compiled:

$$
\left\{\begin{array}{l}
\frac{d}{d t} \frac{\partial T}{\partial \dot{\alpha}}-\frac{\partial T}{\partial \alpha}=Q_{1}-\frac{\partial \Pi}{\partial \alpha} \\
\frac{d}{d t} \frac{\partial T}{\partial \dot{\varphi}}-\frac{\partial T}{\partial \varphi}=Q_{2}-\frac{\partial \Pi}{\partial \varphi}
\end{array}\right.
$$

where $Q_{1}=M_{1}(\alpha, t)$ and $Q_{2}=0$ are generalized external forces in the form of driving moments; $M_{1}(\alpha, t)-$ is the driving moment that creates the actuating mechanism of the manipulator for rotation of its arrow. 
A nonlinear differential equation of motion of the boom system is obtained as a result of the transformation of the system of equations (6). In work [9], the result of the transformation of the Lagrange equation and the obtaining of the dynamic equation of motion of such a boom-type manipulator.

\section{CONCLUSIONS}

The resulting equations of motion can be solved by numerical methods. The result of this study will be useful in building the optimal mode of motion of the manipulator, taking into account the elasticity of the support mechanism.

The use an intelligent drive system of the manipulator it is proposed to which will adjust the speed of its working body for optimal traffic laws by throttling the working fluid with a hydraulic valve for minimize the fluctuations of such a system.

Optimal movement of boom law proposes that the manipulator system identified by minimizing the "energy" of accelerating and jerks.

The damping device with a limiting movement in the reference system of the manipulator another option for reducing the fluctuations of the load is proposed to integrate.

This decision will allow for fluctuations of energy recovery and re-use it in the course of work.

Key words: manipulator, construction cranes, mathematical modeling, dynamics, elastic basic, Lagrange equations.

\section{REFERENCES}

1. Bakun K., Pleshkanovska A., 2018. Methods of determination of territorial resources in conditions of compacted urban development (using Kyiv as an example). Transfer of
Innovative Technologies, Vol. 1(1), 36-49. DOI: 10.31493/tit1811.0104.

2. Urban density done right., 2017. Ideas on densification of cities and other communities, Swedish National Board of Housing, Building and Planning, 50.

3. Sukach M., 2017. Modernizacia ekskavatora dvosekciinoy povorotnoy strilou [Modernization of the excavator with a two-section turning arrow]. Pidvodni tehnologii [Underwater technologies], Vol.07, 28-33. DOI: 10.26884/ 1707.1301 (in Ukrainian).

4. Sukach M.K., Jagodinec V.A., 2009. Ekskavator zi zmishhenoju vissju kopannja. Girnichi, budivel'ni, dorozhni i meliorativni mashini [Mining, construction, road and melioration machines], Nr.73, 67-70 (in Ukrainian).

5. Yongjun Xu, Yanfeng Qiao, Zhiqian Wang, Keping Liu, Yuanchun Li., 2012. Modeling and Variable Structure Control of a Vehicle Flexible Manipulator. Proceedings of the 10th World Congress on Intelligent Control and $\mathrm{Au}$ tomation, July 6-8, Beijing, China.

6. Kalyoncu M., Botsall F.M., 2018. Vibration analysis of an elastic robot manipulator with prismatic joint and a time-varying end mass. The Arabian Journal for Science and Engineering, Vol.29, Nr.1C, 27-38 (available from https://www.researchgate.net/publication/ 228593714_Vibration_Analysis_of_an_Elastic_ Robot_Manipulator_with_Prismatic_Joint_ and_a_Time-Varying_End_Mass).

7. Gaultier P.E. and Cleghorn W.L., 1992. A Spatially Translating and Rotating Beam Finite Element for Modeling Flexible Manipulators, Mechanism and Machine Theory, 27(4), 415433.

8. Yüksel Ş. and Gürgöze M., 1997. On the Flexural Vibrations of Elastic Manipulators with Prismatic Joints. Computers and Structures, 62(5), 897-908.

9. Mischuk D., 2017. Research dynamics of the boom manipulator mounted on elastic resistance. Girnichi, budivel'ni, dorozhni i meliorativni mashini [Mining, construction, road and melioration machines], Nr.90, 11-18 (in Ukrainian). 